\title{
Electro-Acupuncture versus Therapeutic Ultrasound on Coccydynia after Delivery
}

\author{
HEBA F. HAMADTO, M.Sc.*; MAGDA S. MORSY, Ph.D.* and MOHAMED F. ABO EL ENEEN, M.D.** \\ The Departments of Physical Therapy for Women Health*, Faculty of Physical Therapy, Cairo University, Egypt and \\ Obstetrics \& Gynecology**, OM Elmasryeen Hospital
}

\begin{abstract}
Background: Coccydynia is pain and inflammation of the coccyx or tailbone. Therapeutic ultrasound and electroacupuncture are safe and effective methods for reducing chronic coccyx pain.
\end{abstract}

Aim of Study: This study was conducted to determine if therapeutic ultrasound have more effect than electroacupuncture on coccyx pain after delivery at young female.

Subjects and Methods: Thirty primi and multiparous women suffering from coccydynia were participated in this study. They were selected rondomely from the out patient clinic of gynacology and obstetric in Al-Qasr El-Einy Hospital to share in this study, their ages were ranged from 25 to 35 years old and their body mass index (BMI) were not exceed $30 \mathrm{~kg} / \mathrm{m}^{2}$. The participants were assigned into two groups of equal numbers: Group (A) received continuous ultrasound of frequency $1 \mathrm{MHZ}$ and intensity $1.5 \mathrm{~W} / \mathrm{cm}^{2}$ for 5 minutes/ session, 3 times per week for 4 weeks on painful area of coccyx, while group (B) received electro acupuncture for 20 minutes, 3 times per week for 4 weeks. Assessment of pain level in each group was done by using visual analogue scale and plasma cortisol level in the blood at the beginning of the study and at the end of the treatment course.

Results: The results of this study revealed that there was statistically significant improvement in VAS and plasma cortisol level in group (A) than in group (B).

Conclusion: Therapeutic ultrasound are more effective than electro-acupuncure treatment in alleviating pain in women suffering from coccydynia after delivery.

Key Words: Coccydynia - Therapeutic ultrasound - Electroacupuncture - Serum cortisol - Visual analogue scale.

\section{Introduction}

COCCYDYNIA is a medical term, which means the disorder of tailbone pain without any significant radiation or associated low back pain. Women are

Correspondence to: Dr. Heba F. Hamadto, The Department of Physical Therapy for Women Health, Faculty of Physical Therapy, Cairo University, Egypt
5 times more likely to develop coccydynia than men [1]

Many physiologic and psychological factors contribute to its etiology, such as rapid weight loss can be a risk factor because of the loss of mechanical cushioning. The most common etiology of coccydynia is external or internal trauma. External trauma usually occurs due to a backwards fall, leading to a bruised, dislocated, or broken coccyx [2]

Patients with coccydynia classically complain of localized pain in and around coccyx. This pain is associated with sitting and exacerbated when rising from aseated position, it may be worsened with other hip extension activities such as stair climbing [3].

The majority of cases were found to be aggravated by pregnancy and childbirth (postpartum). It appeared very soon after the childbirth, as soon as the sitting position adopted. During pregnancy, the coccyx will be relaxed and loosened to facilitate childbirth; this condition may sometimes result in coccygeal pain or coccygeal injury. During vaginal delivery the sacrococcygeal ligaments may be damaged, and the acute trauma of the coccyx may appear during the passage of the fetus through birth canal. An intrapartum coccygeal fracture or dislocation also supposed to be the cause for postpartum coccydynia [4].

Conservative strategies remain the gold standard treatment for coccydynia, consisting of medications such as nonsteroidal anti-inflammatory agents (NSAIDs) and other analgesics, ice or hot packs, ultrasound, reduced sitting, donut pillow use and other postural adjustments, and physical therapy [5]. 
Coccygectomy may be indicated for patients who have failed conservative management, particularly those with radiographic evidence of hypermobility or subluxation as they appear to exhibit the greatest improvement following this procedure [6].

Therapeutic ultrasound (US) is a form of mechanical energy, and therefore, strictly speaking, not really electrotherapy at all, but does fall into the Electro Physical Agents grouping. Mechanical vibration at increasing frequencies is known as sound energy. The normal human sound range is from $16 \mathrm{~Hz}$ to something approaching 15-20,000 Hz. It is delivered in two modes: (1) Continuous mode in which the delivery of US is non-stop throughout the treatment period; (2) Pulsed mode in which the delivery of US is intermittently interrupted [7]

In order to have a therapeutic effect, absorption of the applied energy is necessary, hence the effectiveness of the modality will vary according to a tissues capacity to absorb the applied energy. Tissues with a higher protein content will absorb US to a greater extent, thus tissues with high water content and low protein content (e.g. blood and fat) absorb little of the US energy whilst those with a lower water content and a higher protein content (e.g. ligament, tendon) will absorb US far more efficiently [8].

The biological effects include changes in nerve conduction velocity, increase in enzymatic activity, changes in contractile activity of skeletal muscles, increase in collagen tissue extensibility, increase in local blood flow, increase in pain threshold, and reducing muscle spasm [9].

Therapeutic biophysical effects of US are classified as thermal and non-thermal. Ultrasonic energy causes soft tissue molecules to vibrate from exposure to the acoustic wave. This increased molecular motion generates frictional heat and consequently increases tissue temperature. This increased temperature, named thermal effects, is thought to cause changes in nerve conduction velocity, increase in enzymatic activity, changes in contractile activity of skeletal muscles, increase in collagen tissue extensibility, increase in local blood flow, increase in pain threshold, and reducing muscle spasm. Acoustic waves cause normally present minute gas pockets in the tissue to develop into microscopic bubbles or cavities. With therapeutic US, stable acoustic cavitation results, whereby the microbubbles pulsate without imploding. This pulsation leads to microstreaming of fluid around the pulsating bubbles. When occurring around cells, this process, referred to as non-thermal effects, is reported to alter cell membrane activity, vascular wall permeability, and facilitate soft tissue healing [10]

Acupuncture has been used as a traditional medical treatment in East Asia for over 3,000 years, and is becoming a popular therapy worldwide for treating various diseases. Acupuncture is a medical intervention in which fine needles are applied to specific parts of the body, called acupuncture points (or acupoints) and penetrated through the muscular or other subcutaneous layers. According to traditional medical theory, acupuncture stimulation facilitates the flow of qi, a life force that is supposedly circulating through the channels called meridians. In electroacupuncture (EA), a small electric current is applied to pairs of acupuncture needles, and studies have indicated that the therapeutic efficacy of EA can be modulated by varying the frequency, intensity, and duration of electrical stimulation [11].

Today the general agreement of scientific community is that acupuncture works though simultaneous activation of multiple pain control mechanisms. Some of main mechanisms involved are increase of endogenous opiates ( 0 -endorphin, encephalin, endomorphin), activation of descendenting pain inhibitory pathway and modulation of nociception in spinal cord through "Gate control" mechanism [12].

\section{Subjects and Methods}

Thirty primi and multiparous women suffering from coccydynia were participated in this study. They were selected rondomely from the out patient clinic of gynacology and obstetric in Al-Qasr ElEiny Hospital and the treatment procedures were carried out in the Physical Therapy Clinic in the period from January 2021 to June 2021 . The women's ages ranged from 25 to 35 years, and their body mass index (BMI) were not exceed $30 \mathrm{~kg} / \mathrm{m}^{2}$. All participants were free from any gynecological diseases, neurological diseases, skin diseases, genital prolapse, back deformity (coccygeal fracture), history of previous trauma to back, previous low back pain, pain in pelvis, pelvic girdle pain, spondylosis, spondylo-lithesis, diabetes, hypertension, pelvic tumors and gastric ulcers. All women were divided into 2 groups equal in number, group A and group B.

Group A were consisted of 15 primi and multi parous women received continuous ultrasound of frequency $1 \mathrm{MHZ}$ and intensity $1.5 \mathrm{~W} / \mathrm{cm}^{2}$ for 5 
minutes/session, 3 times per week for 4 weeks on painful area of coccyx.

Group B were consisted of 15 primi and multi parous women received electro acupuncture for 20 minutes, 3 times per week for 4 weeks.

\section{Evaluating procedures:}

- Each woman in both groups (A \& B) was asked to fill the information sheet and signed on it as her agreement to share in this study before starting the treatment course.

- Weight and height of each woman in both groups (A \& B) was taken before treatment course and BMI was calculated.

- A full instruction about VAS scale was given to each woman in both groups (A \& B). Then, each woman was asked to mark on the line according to her intensity of pain this was done before and after treatment course to detect intensity of pain of each one.

- A blood sample of $3 \mathrm{~cm}$ was drawn from each woman in both groups (A \& B) before and after treatment course and was sent to the laboratory to determine the plasma cortisol level in the blood.

- Each woman was asked to sit on arm chair. The anticubital area was cleaned with a piece of cotton immersed in alcohol. Blood sample was drawn from the anticubital vein from all subjects by disposable sterile syringe.

- All samples were collected in the morning before breakfast for all cases and were sent immediately to the laboratory center for analysis.

\section{Treatment procedures:}

Group A: They were received continuous ultrasound of frequency $1 \mathrm{MHZ}$ and intensity $1.5 \mathrm{~W} / \mathrm{cm}^{2}$ for 5 minutes/session, 3 times per week for 4 weeks on painful area of coccyx. Each participant in this group were asked to lie in the plinth in prone lying position with deviated head to one side and covered by a white sheet except the treated area. The area of the skin which were treated is cleaned with apiece of cotton immersed in alcohol to reduce skin resistance. The ultrasound device was adjusted on frequency $1 \mathrm{MHZ}$ and intensity $1.5 \mathrm{~W} / \mathrm{cm}^{2}$ for 5 minutes and sufficient amount of ultrasound gel which were placed on the transducer head (treatment head) after that the ultrasound device were switched on, the physiotherapist start moving the transducer head on painful area of coccyx in circular movement.
The parameters of U.S device were set as the following:

- Mode: Continuous.

- Intensity: $0.5-1 \mathrm{w} / \mathrm{cm}^{2}$.

- Frequency: $1 \mathrm{M}-\mathrm{HZ}$ sonopuls 400 with a $5 \mathrm{~cm}^{2}$ sound head.

- Duration: 5 minutes.

This session were repeated 3 times per week for 4 weeks.

After finishing the session, the device was switched off and the treatment head was cleaned with a piece of cotton.

Group B: They were received electro acupuncture for 20 minutes, 3 times per week for 4 weeks. Each participant in this group were asked to lie on the plinth in supine lying position and covered by a white sheet except the treated area. At first, the acupoint of coccydynia (LI-4 Hegu) were detected bilaterally and its site were remarkable.

The skin of treated area were cleaned with a piece of cotton immersed in alcohol then the sterilized acupuncture needles were inserted in these acupoints and the electrical stimulator were adjusted at $(100 \mathrm{~Hz})$. Then the electrodes of electrical stimulator were connected to the needles, after that electrical stimulator was switched on for 20 minutes The intensity is increased gradually according to the tolerance of the patient.

After finishing the session, the electrical stimulator was switched off and the needles were removed from the acupoints.

a- Frequency: $(100 \mathrm{~Hz})$.

b- Pluse width: Narrow and shorter pulse (20$60 \mathrm{~ms}$ ).

c- Intensity: until patient feel tingling sensation.

d- Pulse duration: $0.5 \mathrm{~ms}$.

e- Duration of session: 20 minutes.

Additionally, both groups (A \& B) were advised to use well-padded seat with a gel cushion when sitting to decrease coccygeal pressure.

Also, they were advised to use stool softeners and increase fiber and fluids in diet to decrease constipation.

\section{Results}

Patient demographic data:

General characteristics of the two studied groups:

The mean values of age, weight, height and BMI in group A were $30.00 \pm 3.27$ yrs., $84.23 \pm$ 
$3.66 \mathrm{~kg} ., 170.73 \pm 3.79 \mathrm{~cm}$ and $29.05 \pm 0.92 \mathrm{~kg} / \mathrm{m}^{2}$, respectively. While in group B they were $30.30 \pm$ 3.33 yrs., $83.53 \pm 2.81 \mathrm{~kg} ., 169.13 \pm 2.56 \mathrm{~cm}$ and 29.14 $\pm 1.04 \mathrm{~kg} / \mathrm{m}^{2}$, respectively. There was no statistical significant difference between the two groups as regards age $(t=0.249, p=0.805)$, weight $(t=0.587$, $p=0.562)$, height $(t=1.355, p=0.186)$ and BMI $(t=$ $0.243, p=0.810$ ), respectively (Table 1 ).

Comparing the general characteristics of the subjects of both groups revealed that there was no significance difference between both groups in the mean age, weight, height, or BMI ( $p>0.05)$.

Table (1): Demographic features (general characteristics) of the two studied groups.

\begin{tabular}{lllll}
\hline & $\begin{array}{c}\text { Group A } \\
(\mathrm{n}=15)\end{array}$ & $\begin{array}{c}\text { Group B } \\
(\mathrm{n}=15)\end{array}$ & $\begin{array}{c}t- \\
\text { value }\end{array}$ & $\begin{array}{c}p- \\
\text { value }\end{array}$ \\
\hline Age (yrs. $)$ & $30.00 \pm 3.27$ & $30.30 \pm 3.33$ & -0.249 & 0.805 (NS) \\
Weight $(\mathrm{kg})$. & $84.23 \pm 3.66$ & $83.53 \pm 2.81$ & 0.587 & 0.562 (NS) \\
Height $(\mathrm{cm})$ & $170.73 \pm 3.79$ & $169.13 \pm 2.56$ & 1.355 & 0.186 (NS) \\
BMI $\left(\mathrm{kg} / \mathrm{m}^{2}\right)$ & $29.05 \pm 0.92$ & $29.14 \pm 1.04$ & -0.243 & 0.810 (NS) \\
\hline
\end{tabular}

Data are expressed as mean \pm SD. NS $=p>0.05=$ Not significant.

\section{Comparative studies between the two groups} $(A \& B):$

Results of VAS:

Comparison between both groups $(A \& B)$ :

Table (2) and Figs. $(1,2)$ illustrates mean \pm SD for VAS scores before and after treatment for both groups (A \& B).

By comparing the two groups (A \& B) after treatment regarding to VAS scores, it was found that, both groups showed a decrease in pain sensation after treatment, group (A) achieved $91.15 \%$ while group (B) achieved $32.82 \%$ but the percentage of decrease in VAS was more pronounced and more notable in group (A) when compared with group (B), this means that continuous ultrasound was more effective than electro-acupuncture in decreasing pain.

Table (2): Mean values of VAS measured before and after treatment \& percent of decrease in VAS after treatment in both groups (A \& B).

\begin{tabular}{|c|c|c|c|c|}
\hline \multirow{2}{*}{ Variable } & \multicolumn{2}{|c|}{ Group A } & \multicolumn{2}{|c|}{ Group B } \\
\hline & $\begin{array}{c}\text { Before } \\
\text { treatment }\end{array}$ & $\begin{array}{c}\text { After } \\
\text { treatment }\end{array}$ & $\begin{array}{c}\text { Before } \\
\text { treatment }\end{array}$ & $\begin{array}{c}\text { After } \\
\text { treatment }\end{array}$ \\
\hline Mean $\pm \mathrm{SD}$ & $3.73 \pm 0.46$ & $0.33 \pm 0.49$ & $3.87 \pm 0.35$ & $2.60 \pm 0.91$ \\
\hline MD & \multicolumn{2}{|c|}{3.40} & \multicolumn{2}{|c|}{1.27} \\
\hline$t \#$ value & \multicolumn{2}{|c|}{25.968} & \multicolumn{2}{|c|}{6.141} \\
\hline$p$-value & \multicolumn{2}{|c|}{0.001} & \multicolumn{2}{|c|}{0.001} \\
\hline$\%$ of $\downarrow \downarrow$ in VAS & \multicolumn{2}{|c|}{91.15} & \multicolumn{2}{|c|}{32.82} \\
\hline Significance & \multicolumn{2}{|c|}{ Highly significant } & \multicolumn{2}{|c|}{ Highly significant } \\
\hline
\end{tabular}

$\mathrm{MD}=$ Mean difference.

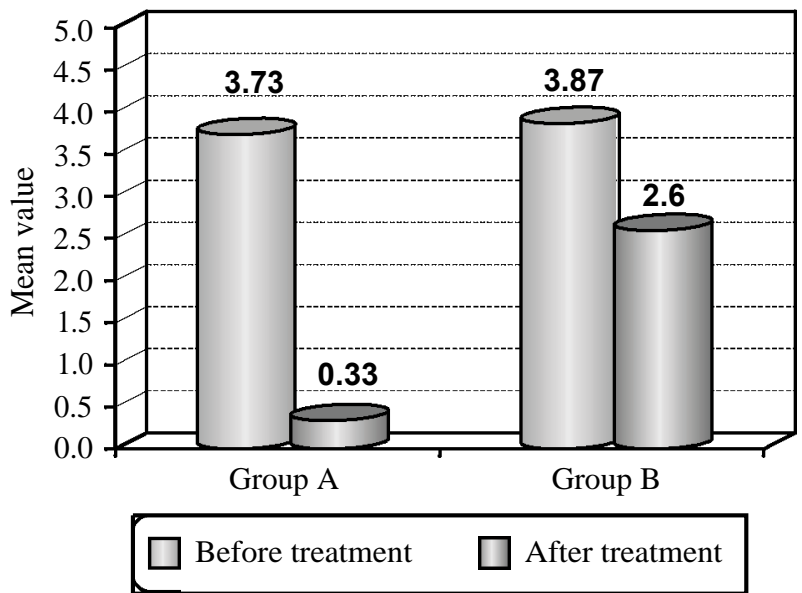

Fig. (1): Illustrates mean values of VAS measured before and after treatment in the two studied groups (A \& B).

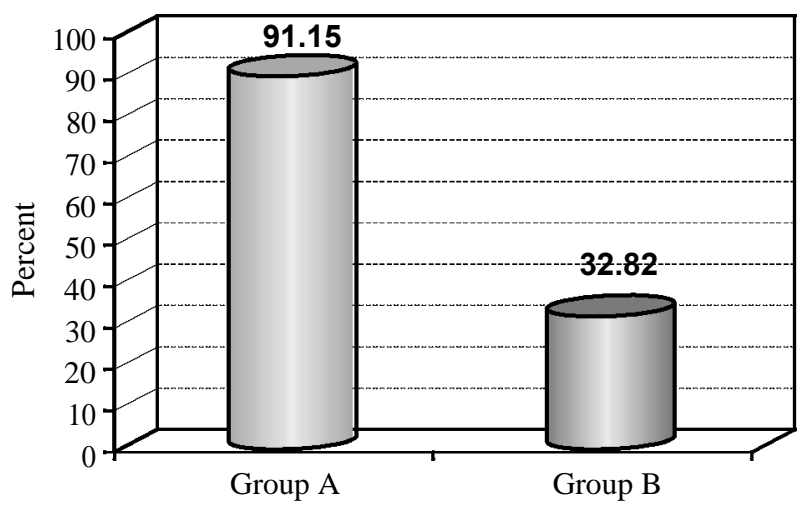

Fig. (2): Percent of decrease in VAS after treatment in both groups (A \& B).

Results of cortisol level:

Comparison between the two groups $(A \& B)$ :

Before treatment the mean \pm SD of serum cortisol level was $17.50 \pm 4.20$ and after treatment was $14.60 \pm 4.15$ with mean difference equal to 2.90 . This difference was a statistically $(p<0.001)$ significant and represented a percentage of decrease in serum cortisol about $16.57 \%$.

Table (3) and Figs. $(3,4)$ illustrates mean \pm SD for serum cortisol before and after treatment for both groups (A \& B).

Table (3): Mean values of serum cortisol measured before and after treatment \& percent of decrease in serum cortisol level after treatment in both groups (A \& B).

\begin{tabular}{|c|c|c|c|c|}
\hline \multirow{2}{*}{ Variable } & \multicolumn{2}{|c|}{ Group A } & \multicolumn{2}{|c|}{ Group B } \\
\hline & $\begin{array}{c}\text { Before } \\
\text { treatment }\end{array}$ & $\begin{array}{c}\text { After } \\
\text { treatment }\end{array}$ & $\begin{array}{c}\text { Before } \\
\text { treatment }\end{array}$ & $\begin{array}{c}\text { After } \\
\text { treatment }\end{array}$ \\
\hline Mean $\pm \mathrm{SD}$ & \multicolumn{2}{|c|}{$17.28 \pm 2.906 .04 \pm 0.77$} & $18.19 \pm 3.17$ & $14.16 \pm 4.36$ \\
\hline MD & \multicolumn{2}{|c|}{11.24} & \multicolumn{2}{|c|}{4.03} \\
\hline$t \#$ value & \multicolumn{2}{|c|}{14.306} & \multicolumn{2}{|c|}{7.007} \\
\hline$p$-value & \multicolumn{2}{|c|}{0.001} & \multicolumn{2}{|c|}{0.001} \\
\hline$\%$ of $\downarrow \downarrow$ in VAS & \multicolumn{2}{|c|}{65.05} & \multicolumn{2}{|c|}{22.16} \\
\hline Significance & \multicolumn{2}{|c|}{ Highly significant } & \multicolumn{2}{|c|}{ Highly significant } \\
\hline
\end{tabular}

$\mathrm{MD}=$ Mean difference. 
By comparing the two groups (A \& B) after treatment regarding to serum cortisol level, it was found that, both groups showed a decrease in serum cortisol level after treatment, group (A) achieved $65.05 \%$ while group (B) achieved $22.16 \%$ but the percentage of decrease in serum cortisol level was more pronounced and more notable in group (A) when compared with group (B), this means that continuous ultrasound was more effective than electro-acupuncture in decreasing serum cortisol level.

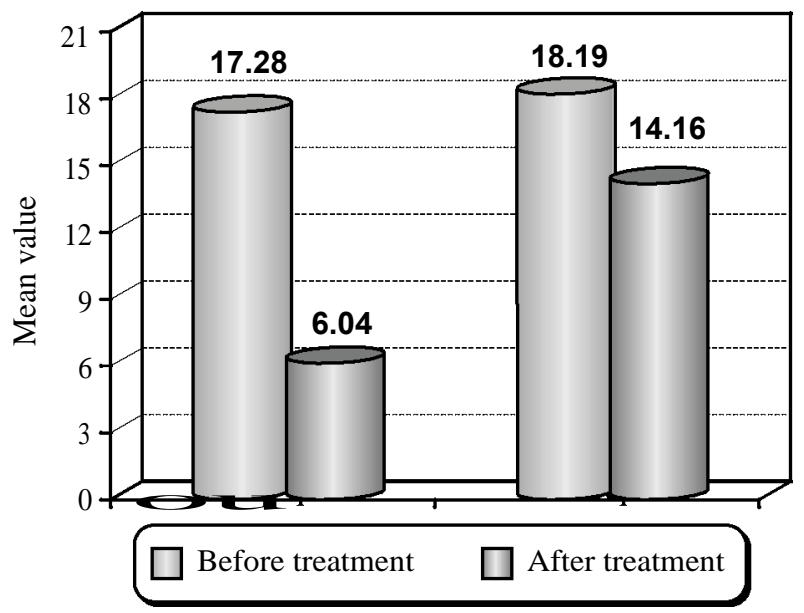

Fig. (3): Illustrates mean values of serum cortisol measured before and after treatment in the two studied groups (A \& B).

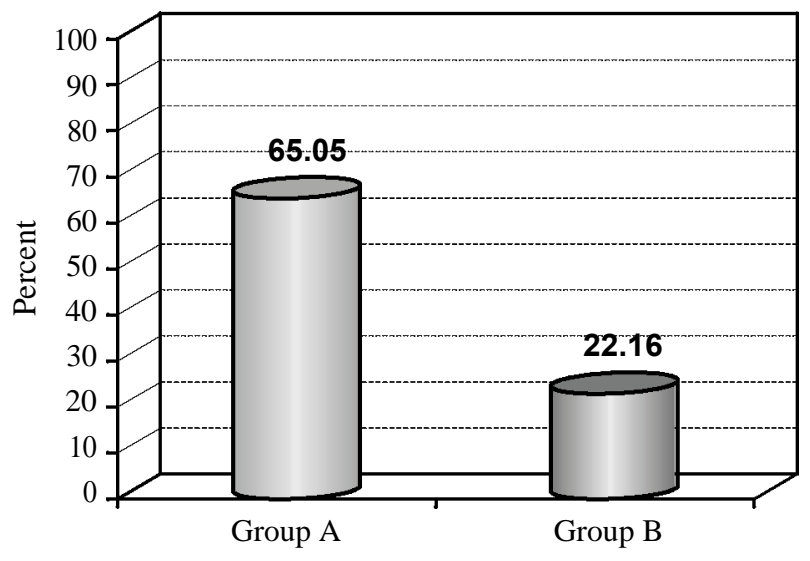

Fig. (4): Percent of decrease in serum cortisol level after treatment in both groups (A \& B).

\section{Discussion}

This study was conducted for women suffering from postpartum coccydynia (immediately after delivery) to investigate if therapeutic ultrasound had more effect than electroacupuncture on treatment of post partum coccydynial pain. Assessment of pain was done by using VAS scale and plasma cortisol level in the blood.
The results showed that therapeutic ultrasound was more effective than electroacupuncture in alleviating pain and sorteness in cases of coccydenia after delivery.

The result of this study is in agreement with the findings of Ali Yadollahpour, Samaneh Rashidi, [13] who demonstrated that, US treatment increases vasodilatation, stimulates vascular endothelial growth factor and angiogenesis, promotes early release of growth factors, and provides greater amounts of high-quality collagen. The overall result of these cellular effects is pain relief, inflammation decreased and accelerated healing.

Also, the result of this study runs in the same line with that of Mustafa Aziz Yildirim, et al., [14] who studied the effectiveness of ultrasound therapy on myofascial pain syndrome of the upper trapezius and found that the effect of continuous US on pain was superior to pulsed and placebo US therapies.

The results of this study came in agreement with the results of Bartkowiak Z, et al., [15] who studied the effects of nerve and tendon gliding exercises combined with low-level laser or ultrasound therapy in carpal tunnel syndrome and demonstrated that Conservative treatment comprising ultrasound or LLLT with a combination of gliding exercises is effective in nonoperative management in patients with a mild and moderate stage of CTS.

The results of this study came in support with the results stated by Rohit Aiyer, et al., [16] who evaluated therapeutic ultrasound (continuous and pulsed) in patients with chronic knee, shoulder and hip pain. Their search strategy identified 8 trials for knee, 7 trials for shoulder and 0 trials for hip that met the criteria for inclusion. All 8 trials showed improvement in knee pain, and of these studies 3 showed statistical significance improvement for therapeutic ultrasound versus the comparator. For shoulder pain, all 7 trials showed reduction in pain.

The results of this study are supported by Zhu, et al., [17] who studied the effect of acupuncture treatment in patients with low back pain and the result showed that acupuncture benefits all parts of the body. Acupuncture can significantly reduce the pain and inflammation in the affected area, reduce the disability, improve the function, reduce the functional limitations and correct the blood and Qi flow in the affected area. Acupuncture as a treatment for low back pain is a very effective treatment giving very satisfying and positive results in a short time of period. The percentage of cured patients (relieved of the symptoms) is $100 \%$ which 
is a clear indicator of the success of acupuncture in the treatment of low back pain.

The results of this study came in agreement with the results of Shen Y, et al., [18] who studied the effect of electroacupuncture for lumbar disc herniation and found that electroacupuncture is effective, safe, operable, low-cost and promising for $\mathrm{LDH}$, therefore it has been prevalent over the last few decades to reduce the need for surgery.

\section{Conclusion:}

On the basis of data obtained in present study, therapeutic ultrasound has beneficial effects in alleviating pain in cases of coccydynia after delivery.

\section{References}

1- MAIGNE J.Y. and CHATELLIER G.:Comparison of three manual coccydynia treatments: A pilot study. Spine, 26: E479-E483, 2001.

2- NATHAN S.T., FISHER B.E. and ROBERTS C.S.: Coccydynia: A review of pathoanatomy, aetiology, treatment and outcome. J. Bone Joint Surg. Br. Dec., 92 (12): 1622$1627,2010$.

3- FOGEL G., CUNNINGHAM P. and ESSES S.: Coccygodynia: Evaluation and management. J. Am. Acad. Orthop. Surg., 12: 49-54, 2004.

4- REZA MAULANA, NUR WAHYUNIATI and IMAI INDRA: Postpartum Coccydynia: An Anatomy Overview September 9-11, Banda Aceh, Indonesia, 2015.

5- GRASSI R., LOMBARDI G., REGINELLI A., et al.: Coccygeal movement: Assessment with dynamic MRI. Eur. J. Radiol., 61: 473-9, 2007.

6- RAVI PATEL, ANOOP APPANNAGARI and PETER G. WHANG: Coccydynia. Curr. Rev. Musculoskelet Med., 1: 223-226, 2008.

7- GRAZIO S., MARKULINÈIÆ B., NEMÈIÆ T., GRUBISIC F., MATIJEVIÆ V., SKALA H., KASUN B. and KOPRIVNJAK V.: Trgovec: Effect of intereferential current and therapeutic ultrasound on lumbar spine range of motion in patients with chronic low back pain. In Proceedings of the ${ }^{7^{t h}}$ Mediterranean Congress of Physical and Rehabilitation Medicine: Portoro (Slovenia), 18-21 September, 2008.
8- WATSON T.: Electrotherapy and tissue repair. SportexMedicine, 29: p.7-13, 2006.

9- CHAN A.K., MYRER J.W., MEASOM G.J. and DRAPER: Temperature Changes in Human Patellar Tendon in Response to TherapeuticUltrasound. J. Athl. Training, 33 (2): 130-135, 1998

10- ALLEN R.J.: Physical agents used in the management of chronic pain by physical therapists. Phys. Med. Rehabil Clin. N. Am., 17: 315-345, 2006.

11- JIN H., GUO J., LIU J., et al.: Anti-inflammatory effects and mechanisms of vagal nerve stimulation combined with electroacupuncture in a rodent model of TNBSinduced colitis. Am. J. Physiol. Gastrointest Liver Physiol., 313 (3): G192-G202, 2017.

12- HAN J.: Acupuncture analgesia: Areas of consensus and controversy. Pain, 152 (3 Suppl): 41-8, 2011.

13- ALI YADOLLAHPOUR and SAMANEH RASHIDI: A review of mechanism of actions of ultrasound waves for treatment of soft tissue injuries, International Journal of Green Pharmacy, (Suppl) 11 (1): Jan-Mar 2017.

14- MUSTAFA AZIZ YILDIRIM, KADRIYE ÖNES, GÖKSEN GÖKSSENOGLU: Effectiveness of Ultrasound Therapy on Myofascial Pain Syndrome of the Upper Trapezius: Randomized, Single-Blind, Placebo-Controlled Study Arch. Rheumatol., 33 (4): 418-423, 2018.

15- BARTKOWIAK Z., ELIKS M., ZGORZALEWICZSTACHOWIAK M. and ROMANOWSKI L.: The effects of nerve and tendon gliding exercises combined with lowlevel laser or ultrasound therapy in carpal tunnel syndrome. Indian J. Orthop., 53: 347-52, 2019.

16- ROHIT AIYER, M.D., SELAIMAN A. NOORI, M.D., KE-VIN CHANG, M.D., BOYOUN JUNG, M.D., ABDULLAH RASHEED, M.D., NITIN BANSAL, M.D., EINAR OTTESTAD, M.D. and AMITABH GULATI, M.D.: Therapeutic Ultrasound for Chronic Pain Management in Joints: A Systematic Review, Pain Medicine, Volume 21, Issue 7, Pages 1437-1448, July 2020.

17- ZHU J.H., ARSOVSKA B. and KOZOVSKA K.: Acupuncture Treatment in Patients with Low Back Pain. Yangtze Medicine, 2: 203-207, 2018.

18- SHEN Y., ZHOU Q., ZHANG L., et al.: Electroacupuncture for lumbar disc herniation: A protocol for systematic review and meta-analysis. Medicine (Baltimore), 99 (17): e19867, 2020. 


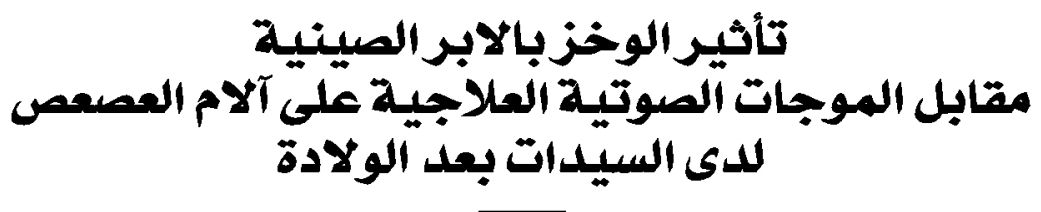

الخلفية: آلام العصعص هو وجود آلام والتهابات فى الفقرات العصعصية. الموجات فوق الصوتية والوخز بالابر الصينية تعتبر من الطرق

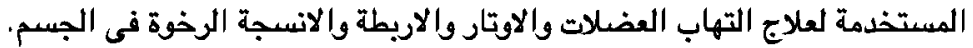

الهدف: أجريت هذه الدراسة لتحديد ما إذا كانت الموجات فوق الصوتيّة لها تأثير فعال عن الوخز بالابر الصينية على علاج آلام العصعص

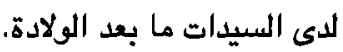

الطرق والأساليب: شاركت فى هذه الدراسة ثلاثون سيدة يعانف من آلام العصعص بعد الولادة من القسم الخارجى لمستشفى القصر

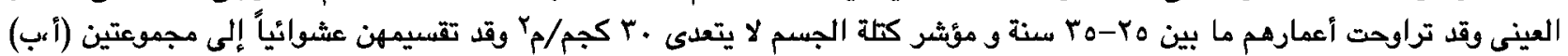

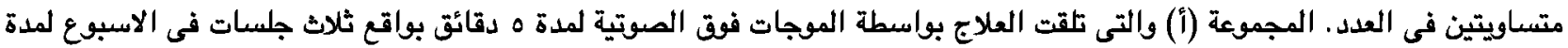

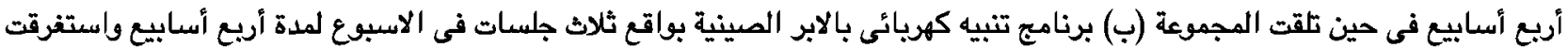

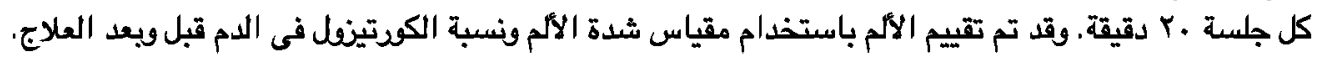

النتائج: بعد نهاية مدة العلاج أظهرت نتائج الدراسة الحالية وجود تحسن ذو دلالة إحصائية في مقياس شدة الألم ونسبة الكوتينفل فى

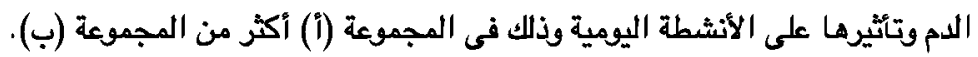

الخلاصة: الموجات فوق الصوتية أكثر فعالية من التبيه بالوخز بالابر الصينية فى تحسين آلام العصعص لدى السيدات ما بعد الولادة. 